\title{
Glioblastoma multiforme cells: Expression of erythropoietin receptor and response to erythropoietin
}

\author{
DONG YIN ${ }^{1}$, HIROSHI KAWABATA ${ }^{1}$, OXANA TCHERNIAMTCHOUK ${ }^{3}$, \\ THIEN HUYNH ${ }^{1}$, KEITH L. BLACK ${ }^{2}$ and H. PHILLIP KOEFFLER ${ }^{1}$ \\ ${ }^{1}$ Division of Hematology/Oncology, ${ }^{2}$ Maxine Dunitz Neurosurgical Institute, ${ }^{3}$ Pathology and Lab Medicine, \\ Cedars-Sinai Medical Center, UCLA School of Medicine, Los Angeles, CA 90048, USA
}

Received June 18, 2007; Accepted August 10, 2007

\begin{abstract}
Erythropoietin (EPO) is a glycoprotein hormone that is a primary regulator of erythropoiesis. In erythroid cells, EPO binds to its receptor (EPOR) to stimulate growth, prevent apoptosis, and promote differentiation. Both EPO and EPOR have been found in many normal and tumor nonerythroid cell types. EPO has been reported to stimulate proliferation and inhibit apoptosis of cancer cells. In this study, we found that EPOR is expressed in brain tumors, glioma cell lines and explants, as well as, normal brain. EPO slightly stimulated the growth of serum-starved glioma cells. Furthermore, EPO increased the phosphorylation of AKT through the PI3K pathway in the glioma cells. It also increased the phosphorylation of ERK, c-jun, JNK, as well as, the expression of BCL-2 and BCL-xl in these cells. These results suggest that the EPO-EPOR pathway may promote glioma cell survival and could become a therapeutic target in brain tumors.
\end{abstract}

\section{Introduction}

Erythropoietin (EPO), a glycoprotein hormone, is a primary regulator of erythropoiesis (1). In erythroid cells, EPO binds to its receptor (EPOR) to activate multiple signaling pathways, stimulating growth, preventing apoptosis, and promoting differentiation in these cells $(2,3)$. Although the classic role of EPO is the regulation of red blood cell production, both EPO and its receptor have been localized to several nonhematopoietic tissues including neurons (4), endothelial cells (5), megakaryocytes (6), as well as, cancer cells of the breast (7), kidney (8), head and neck (9) and endometrium (10).

Correspondence to: Dr Dong Yin, Division of Hematology and Oncology, Cedars-Sinai Medical Center, UCLA School of Medicine, 8700 Beverly Boulevard, Davis Building 5022 Room, Los Angeles, CA 90048, USA

E-mail: dong.yin@cshs.org

Key words: erythropoietin, erythropoietin receptor, glioblastoma multiforme
The diverse expression of EPOR and production of EPO suggest that the function of EPO-EPOR extends beyond erythropoiesis. A new role of this glycoprotein has recently been suggested in the brain: prevention of ischaemic-, hypoxicand toxic-induced death of neurons (11). EPO also stimulated angiogenesis via EPOR in endothelial cells in vitro and in vivo (12).

In other studies, EPOR was activated by EPO and stimulated the proliferation of human and murine renal adenocarcinoma cell lines (8). Also, this cytokine stimulated both the tyrosine phosphorylation and proliferation of MCF-7 and BT549 breast cancer cells (7). These findings suggested that administration of EPO to patients with either kidney or breast cancer has the potential to promote tumor growth. Two recent clinical trials reported that an adverse outcome was associated with adjunctive EPO therapy for patients with either metastatic breast cancer or head and neck cancer who were undergoing chemotherapy or radiotherapy, respectively. The progressionfree survival of these patients was worse than their placebotreated counterparts $(13,14)$. Additionally, blockade of the EPO signal with either a monoclonal antibody against EPO or a soluble EPOR, inhibited the growth of human ovarian and uterine cancer xenografts in nude mice; this was associated with the death of the cancer cells and the surrounding capillary endothelial cells (15).

In this study, we found that EPOR was expressed in glioblastoma multiforme (GBM) explants and cell lines, as well as normal brain cells. Also, we demonstrated that the downstream signaling pathway of EPOR was stimulated after addition of EPO to GBM cells.

\section{Materials and methods}

Patient samples and cell culture. All clinical samples were obtained at the time of surgery after the pathology specimens had been secured. Each sample was quick frozen in liquid nitrogen and stored at $-70^{\circ} \mathrm{C}$ until being processed. Primary GBM explants were established from patients with glioblastoma multiforme undergoing surgery. These tumor specimens were immediately transported to the laboratory, finely minced to single cell suspension and cultured in $100 \mathrm{~cm}^{2}$ tissue culture plastic dishes containing complete medium [Ham's F-12/DME High Glucose medium (Irvine Scientific, Santa Ana, CA), $10 \%$ fetal calf serum (Gemini Bio-Products, 
A

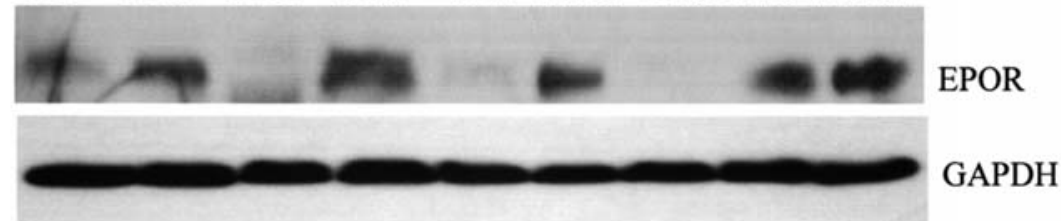

B

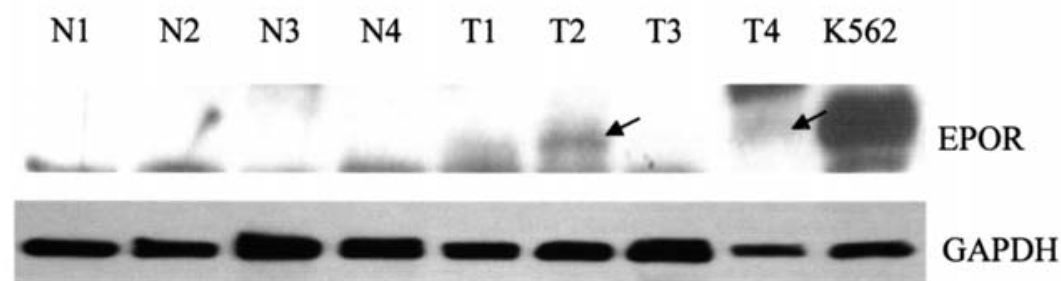

$\mathrm{C}$

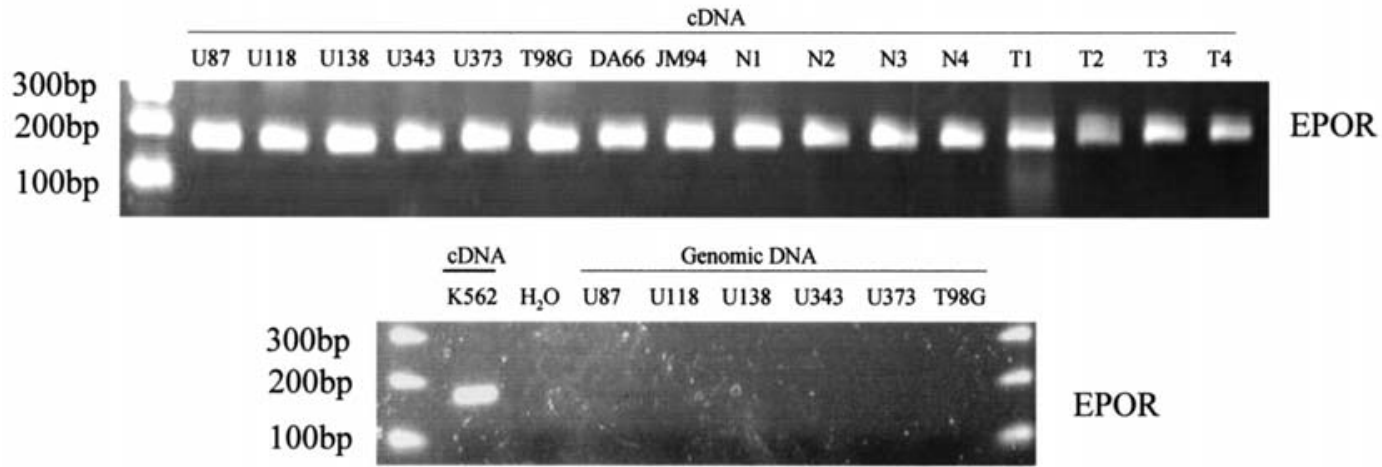

D

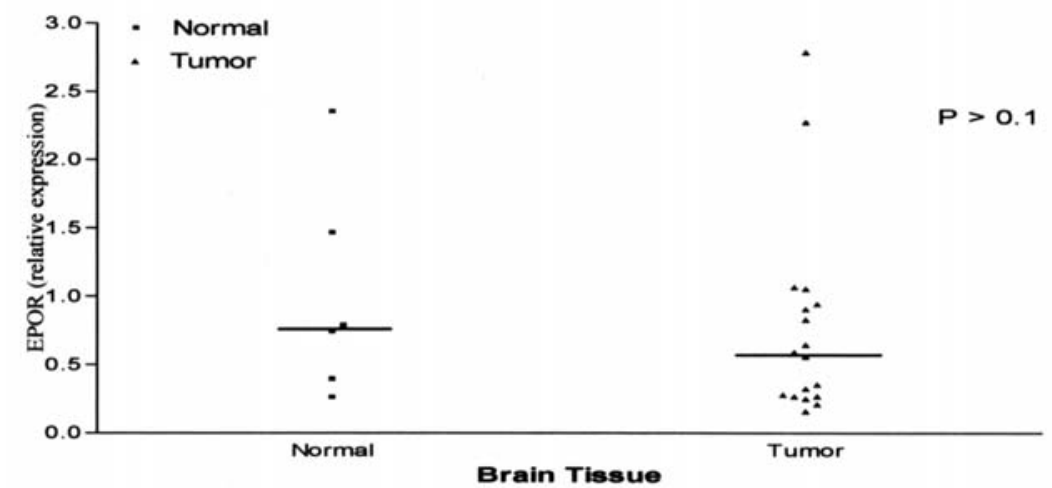

Figure 1. Expression of EPOR in glioma cells and fresh tissues. A and B, Protein was extracted from glioma cell lines (U87, U118, U138, U343, U373, T98G) and glioma explants (DA66, JM94), and normal brain tissue (N); and fresh glioblastoma samples (T). Levels of protein expression of EPOR were detected by Western blotting. C, mRNA expression of EPOR was examined in GBM cell lines, explants, normal brain tissue and GBM tumor tissues by RT-PCR. K562 as positive control, $\mathrm{H}_{2} \mathrm{O}$ as blank control, and genomic DNA from 6 glioma cell lines were tested as primers specific reaction control and showed that the RT-PCR data were not a result of DNA contamination. Furthermore, PCR product was cut from the gel and sequenced confirming that the PCR product was EPOR (data not shown). D, mRNA was extracted from 6 normal brains and 18 GBM; EPOR mRNA was measured by real-time RT-PCR (solid lines show the median value of expression).

Calabasas, CA), $10 \mathrm{U} / \mathrm{ml}$ penicillin-G, $10 \mathrm{mg} / \mathrm{ml}$ streptomycin (Gemini Bio-Products) and $2 \mathrm{mM}$ glutamax-1 (Invitrogen, CA). Written informed consent for research use of tumor tissue was obtained from each patient prior to surgery, according to a protocol approved by the institutional ethics committee. GBM cell lines were maintained in Dulbecco's modified Eagle's medium (Gibco, BRL) with $10 \%$ fetal calf serum (Gemini Bio-Products), $10 \mathrm{U} / \mathrm{ml}$ penicillin-G, and
$10 \mathrm{mg} / \mathrm{ml}$ streptomycin (Gemini Bio-Products). All cells were incubated at $37^{\circ} \mathrm{C}$ in $5 \% \mathrm{CO}_{2}$.

RNA isolation and reverse transcription PCR. mRNAs were isolated from 18 quick-frozen GBM samples and 6 normal brain samples using TRIzol reagent (Invitrogen) according to the manufacturer's instructions. RNA $(2 \mu \mathrm{g})$ was reversetranscribed with random primers (Invitrogen) and Super- 
Script $^{\mathrm{TM}}$ II reverse transcriptase (Invitrogen) in $20 \mu 1$ reaction volume. The cDNA was used for real-time PCR.

Primers and probes. Primers of EPOR gene for real-time PCR were designed employing software PRIMER3 (http://wwwgenome.wi.mit.edu/cgibin/primer/primer3www.cgi) according to the nucleotide sequences of Genebank accession number M60459, EPOR-F, 5'-atcctgacgctctccctcat; EPOR-R, 5'-agc cacagctggaagttacc; probe 5'-ggtgctgctgaccgtgctcg. Real-time RT-PCR was performed in reaction buffer TaqMan Universal PCR Master Mix, $100 \mathrm{nM}$ probe and $300 \mathrm{nM}$ primers in a total volume of $25 \mu \mathrm{l}$. After a denaturation step of $10 \mathrm{~min}$ at $95^{\circ} \mathrm{C}$, two-step amplification conditions were 50 cycles of $15 \mathrm{sec}$ at $95^{\circ} \mathrm{C}, 60 \mathrm{sec}$ at $60^{\circ} \mathrm{C}$. Amplification and product detection were performed with an $\mathrm{iCycler}_{\mathrm{iQ}} \mathrm{Q}^{\mathrm{TM}}$ system (Bio-Rad, Hercules, CA). We used the B-actin cDNA to normalize the expression data of EPOR. Primers and probe of ß-actin were: 5'-TCCCTGGAGAAGAGCTACGA (forward), 5'-AGGAAGGAAGGCTGGAAGAG (reverse), 5'-CAATG AGCGGTTCCGCTGCC (probe). All experiments were done in triplicate. The variance of threshold cycle value between the triplicates was $<5 \%$. The target gene amount was divided by the endogenous reference amount to obtain a normalized target value. The relative expression level of target gene was also normalized to a calibrator (mean value). We selected the mean value of normal brain samples as a calibrator. In the final results, the relative expression of each sample was shown as $\mathrm{N}$-fold difference to the calibrator.

Western blot analysis. Cells were harvested for total cell lysates with RIPA buffer (1\% Nonidet P-40, $0.5 \%$ sodium deoxycholate, $0.1 \%$ SDS, $50 \mathrm{mM}$ Tris- $\mathrm{HCl}, \mathrm{pH} 7.5)$ containing a protease inhibitor mixture (Roche Diagnostics $\mathrm{GmbH}$, Mannheim, Germany), as well as, $1 \mathrm{mM} \mathrm{NaF}$ and $1 \mathrm{mM}$ $\mathrm{NaVO}_{4}$. The lysates $(30 \mu \mathrm{g})$ were denatured in the sample buffer and then subjected to 4-15\% SDS-PAGE followed by electrotransfer to polyvinylidene difluoride membrane. Antip-AKT was from Cell Signaling Technology (Beverly, MA). Anti-EpoR antibody (M-20, sc-697; anti-mouse EpoR) and other antibodies were from Santa Cruz Biotechnology (Santa Cruz, CA).

Akt kinase assay. Akt kinase activity was analyzed by IP/kinase assay following the protocol provided by Cell Signaling Technology. Briefly, U87 cell extracts $(200 \mu \mathrm{l})$ were incubated for $2 \mathrm{~h}$ with immobilized Akt $1 \mathrm{G} 1$ monoclonal antibody. After extensive washing, the kinase reaction was performed in the presence of $200 \mu \mathrm{M}$ of cold ATP and GSK3ß substrate. Phosphorylation of GSK3ß was measured by Western blotting using phospho-GSK3ß antibody.

Statistical analysis. The Student's t-test was used to compare data from two groups.

\section{Results}

The expression of EPOR in GBM cell lines (U87, U118, U138, U343, U373, T98G) and GBM explants (DA66, JM94) (Fig. 1A), as well as, fresh GBM and normal brain tissue (Fig. 1B) was examined by Western blotting. EPOR
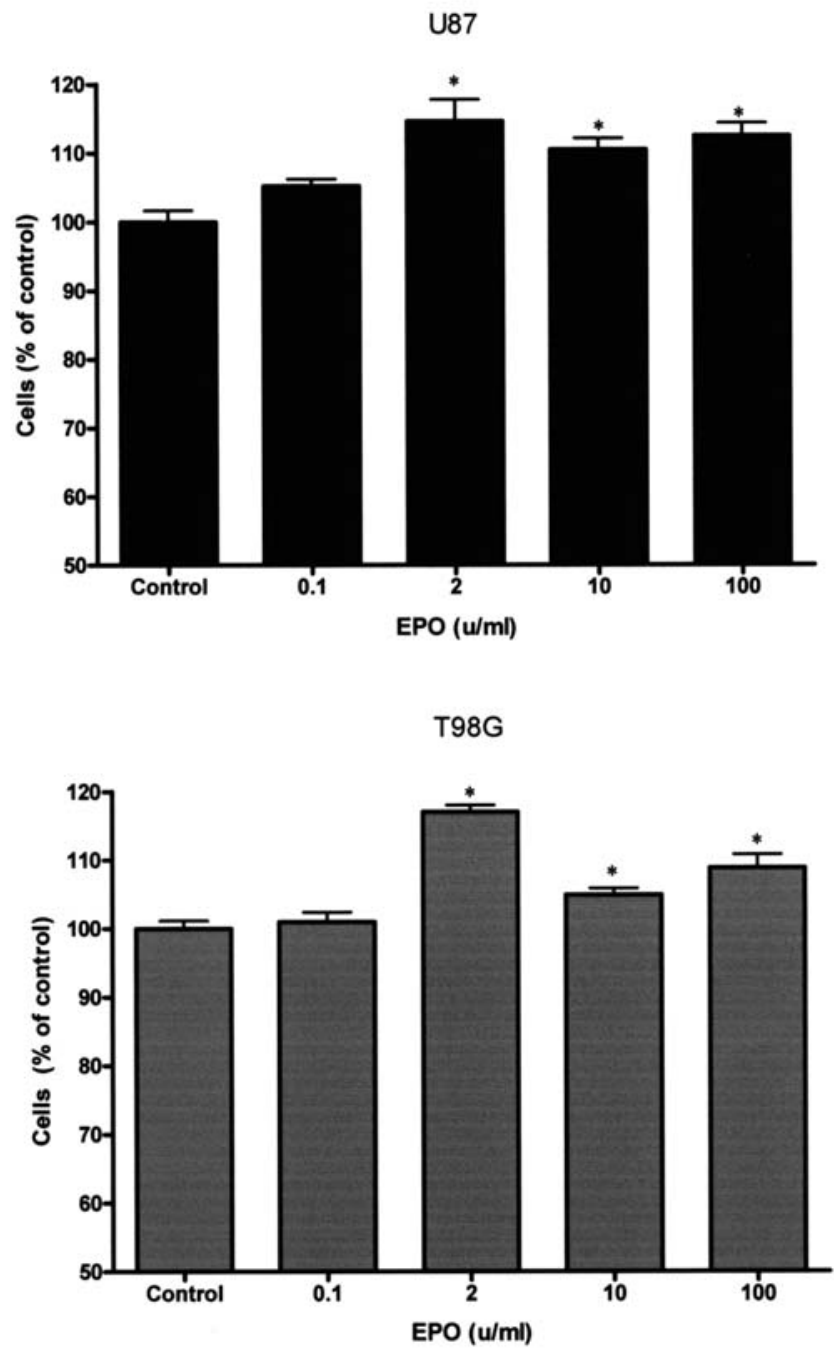

Figure 2. EPO stimulated growth of glioma cells in serum-free medium. U87 and T98G GBM cells were trypsinized, washed 3 times and cultured in serum-free medium for $72 \mathrm{~h}$ with/without EPO. Cell numbers were measured by MTT ( ${ }^{*} \mathrm{p}<0.05$ compared to control).

expression was detected in U87, U118, U343, T98G, JM94 and GBM samples T2 and T4. RT-PCR showed that the mRNA of EPOR was found in all of normal brain and GBM cells (Fig. 1C, top panel) and sequencing confirmed that the product of RT-PCR was EPOR (data not shown). The reverse PCR primer used in this experiment crossed two exons of EPOR, no product was detected when using genomic DNA as a template for PCR (Fig. 1C, bottom panel). EPO levels were below the level of detection when condition medium from U87 and T98G GBM cells ( $1 \times 10^{6}$ cells cultured for 2 days in $10 \mathrm{ml}$ medium) were examined by commercial ELISA (data not shown). The mRNA expression of EPOR was examined by real-time PCR in normal brain and brain tumor tissues. Levels of EPOR mRNA were about the same in both (Fig. 1D).

The U87 and T98G GBM cells were trypsinized, washed 3 times and cultured in serum-free medium for $72 \mathrm{~h}$ with different concentration of EPO. We repeatedly found that the number of cells increased by $10-20 \%$ in the serum-free medium with addition of EPO as measured by MTT (p<0.05) (Fig. 2). However, growth of these cells was not significantly different 


\section{A}

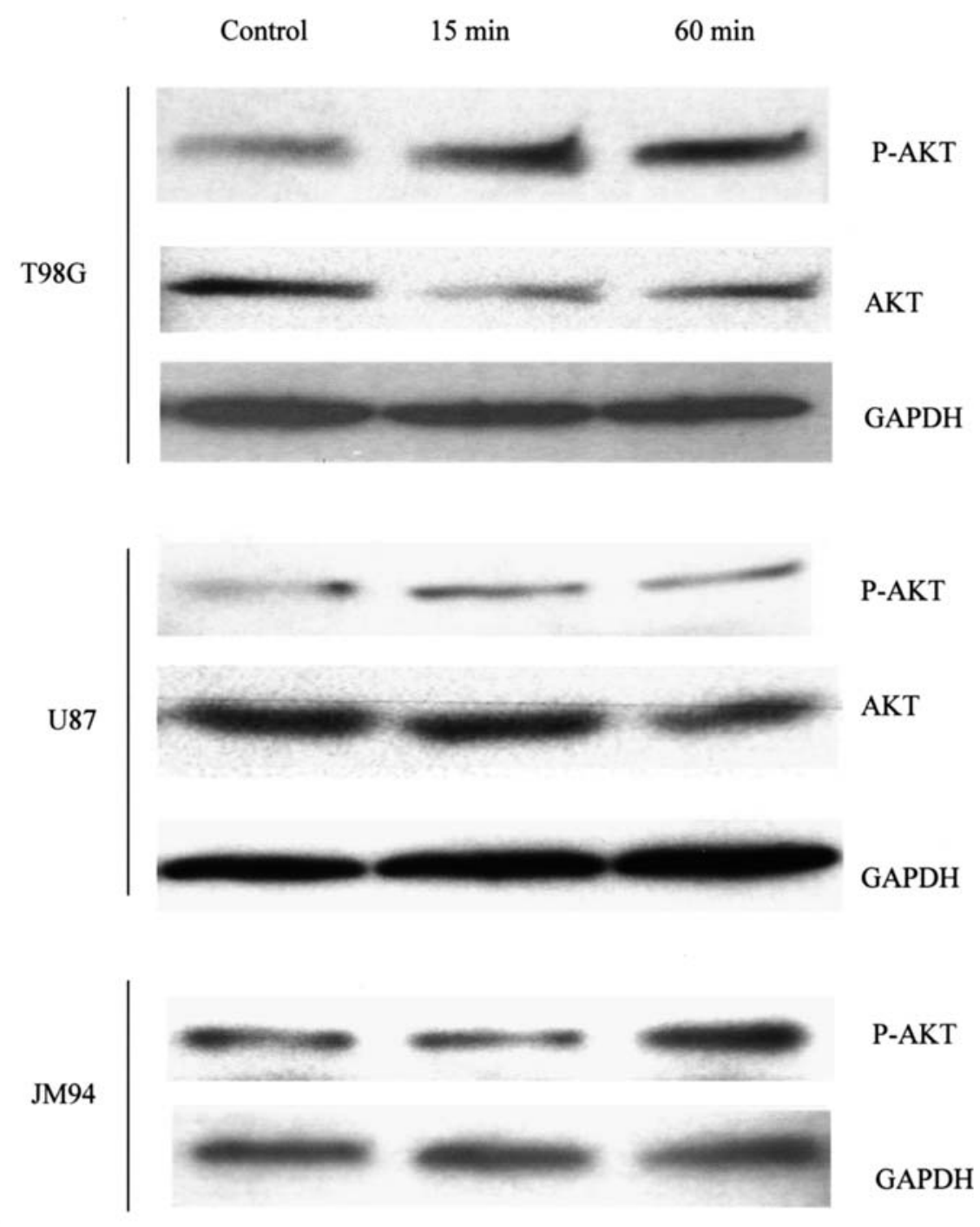

B
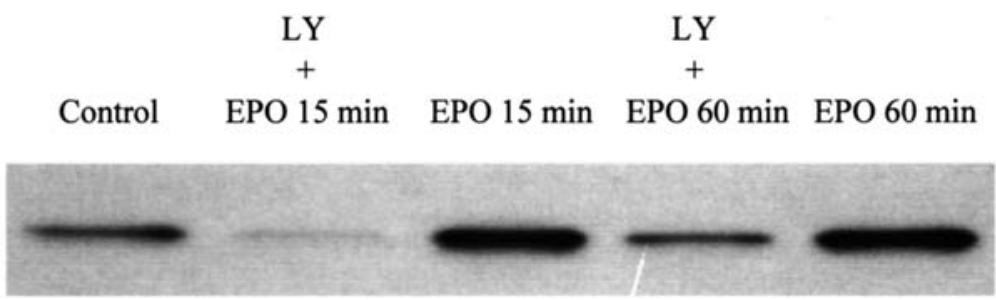

p-GSK3 3

Figure 3. EPO stimulated AKT phosphorylation through PI3K in GBM. A, GBM cell lines (U87, T98G) and GBM explants (JM94) were treated with 2 U/ml EPO for 15 and $60 \mathrm{~min}$. Phosphorylated AKT was detected by Western blotting GAPDH served as a loading control. B, Glioma cells (U87) were cultured with $2 \mathrm{U} / \mathrm{ml} \mathrm{EPO}$ for either 15 or 60 min either with or without pre-treatment for $1 \mathrm{~h}$ with the PI3K inhibitor LY294002 (LY). Lysates of U87 cell were incubated for $2 \mathrm{~h}$ with immobilized Akt 1G1 monoclonal antibody. After extensive washing, the kinase reaction was performed in the presence of ATP and substrate (GSK3ß). Phosphorylation of GSK3ß was measured by Western blotting using phospho-GSK3ß antibody.

when they were cultured in either $1 \%$ or $10 \%$ serum containing culture medium plus the addition of EPO $(0.1 \mathrm{U} / \mathrm{ml}$ to $100 \mu / \mathrm{ml}$, data not shown).

The effect of EPO on cell growth in serum-free conditions suggested that EPO could regulate signal transduction through its receptor (EPOR) in glioma cells. Using Western blotting, we found that EPO (1 U/ml, $15 \mathrm{~min}$ or $60 \mathrm{~min})$ increased levels of phosphorylated AKT in T98G and U87 glioma cell lines, as well as, and JM94 glioma explants (Fig. 3A). The EPO-stimulated activity of AKT was blocked by the PI3-K inhibitor LY90024 (Fig. 3B). These results suggest that the EPO stimulated AKT in GBM cells occurred, 
U87

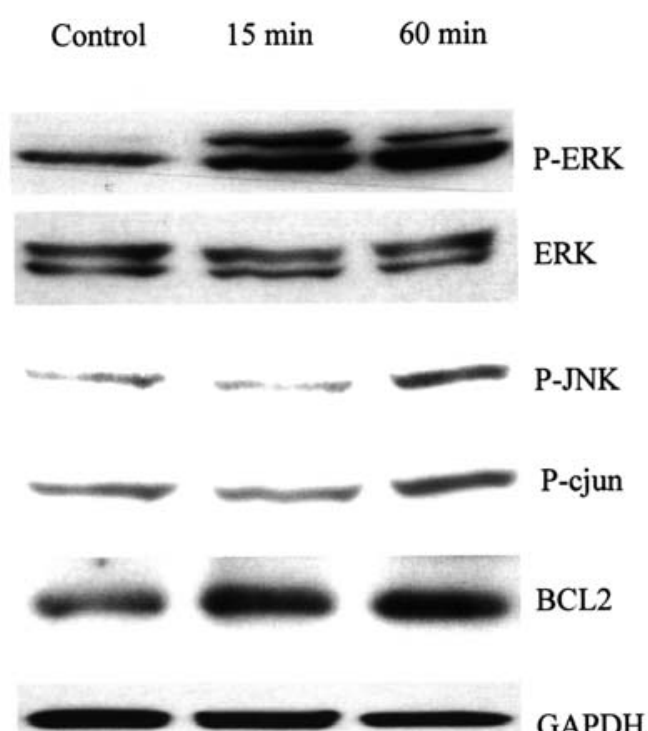

T98G

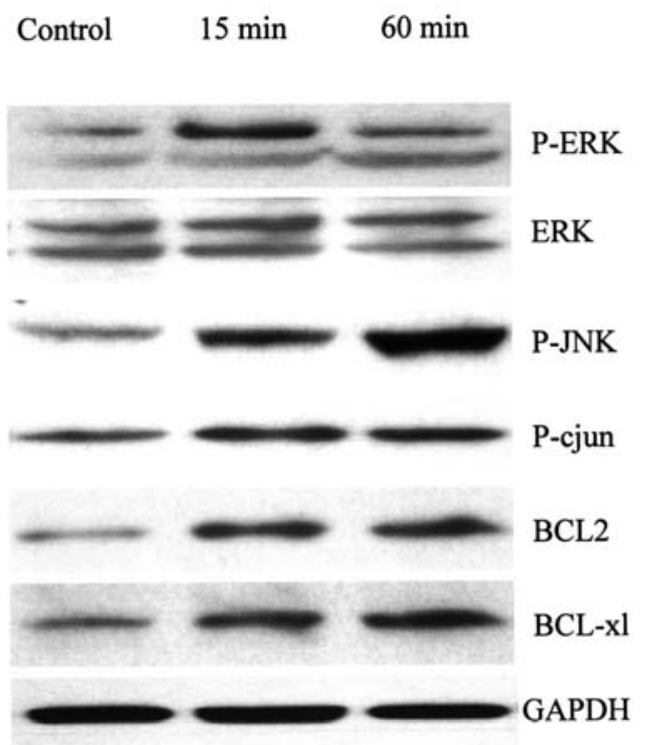

P-ERK ERK P-JNK GAPDH

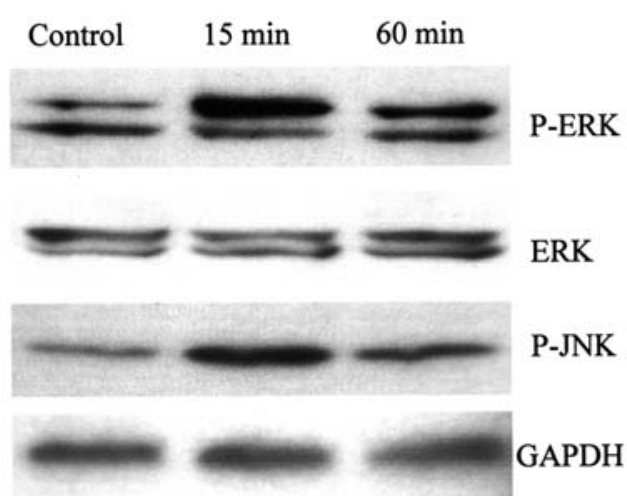

at least in part, through the PI3-K pathway. In addition, several proteins involved in other EPO signaling pathways were activated by EPO in the GBM cell lines and explants, including p-ERK, p-JNK, and p-c-Jun (Fig. 4). Also, EPO increased expression of the anti-apoptotic BCL2 in U87 and T98G, and BCL-xl in T98G glioma cells (Fig. 4).

\section{Discussion}

EPO and EPOR are expressed in the normal central nervous system (CNS) and probably have an important neuroprotective function $(7,16)$. Increasing levels of EPO and EPOR expression have been reported in brain tissue during either hypoxia or ischemia (16). One of the neuroprotective mechanism is the repression of apoptosis by EPO, either by maintenance of Bcl-2 and Bcl-xl expression (16) or by inactivation of caspases (2). For example, EPO treatment of whisker-barrel neonatal rats increased STAT- 5 and Bcl-2 levels in the brain cortex, markedly attenuated apoptotic cell death and reduced ischemic infarcts in the brain (17). Also, circulating EPO can enter the CNS (18). Ischemic stroke patients have been given intravenous injections of recombinant human erythropoietin (rHuEPO) within $5 \mathrm{~h}$ of onset of symptoms (19). EPO crossed into the cerebrospinal fluid (CSF) and was at a 60-100-fold higher concentration than in the CSF of the control group. This clinical trial suggested that EPO-treated patients had greater and earlier improvements than the control patients, with smaller areas of damaged brain tissue (19).

Recombinant EPO has been used frequently in cancer patients to prevent or treat anemia associated with cancer and cancer therapy. Several clinical trials evaluating the beneficial effects of EPO in cancer care have shown improved quality of life and survival in these individuals (20). However, both the ability of EPO to stimulate physiologic and pathologic angiogenesis, and the expression of both EPO and EPOR in cancer cells and vascular endothelium suggest that the EPO-EPOR pathway might exert a direct effect on growth and anti-apoptosis of tumor cells and stimulate angiogenesis to the tumor cells $(14,21)$.

During erythroid maturation, EPO regulates red cell numbers in part via inhibition of apoptosis by upregulation of the antiapoptotic protein Bcl-xl (22). In this study, we found 
that EPO enhanced expressiuon of the antiapoptotic proteins, Bcl-2 and Bcl-xl, suggesting that stimulation of this pathway might contribute to survival of brain tumor cells.

The PI3K/Akt pathway contributed to EPO mediated antiapoptosis in injured ganglion cells (RGCs). Akt phosphorylation was increased by EPO treatment (23). The EPOstimulation of growth of axons was blocked by an inhibitor of PI3K (LY294002) (23). Also, EPO inhibited apoptosis in breast cancer cells via an Akt-dependent pathway (24). Similarly, in our study, the PI3K/Akt pathway was stimulated by EPO. In addition, phosphorylation of extracellular signalregulated kinase (ERK) was increased by EPO in GBM explants and cell lines. A recent study showed that EPO activates the mitogen-activated protein kinase (MEK) and ERK protein, and promotes migration of MCF-7 breast cancer cells (23). Taken together, EPO may affect the survival of both normal and cancerous brain cells. We also found that the EPO receptor when stimulated by EPO in brain cancer cells, resulted in their activation of secondary signaling pathways such as p-ERK, p-AKT, p-JNK and p-Jun. This study shows that GBM signaling pathway can be stimulated by EPO.

\section{Acknowledgements}

This work was supported in part by National Institutes of Health, Inger Fund, and Parker Hughes Trust, as well as, a grant from the Maxine Dunitz Neurosurgical Institute, Cedars-Sinai Medical Center. H.P.K. is a member of the Molecular Biology Institute and Jonsson Comprehensive Cancer Center at UCLA, and holds the endowed Mark Goodson Chair of Oncology Research at Cedars-Sinai Medical Center/UCLA School of Medicine. The manuscript is dedicated to the memory of Matt Schreck.

\section{References}

1. Tilbrook PA and Klinken SP: Erythropoietin and erythropoietin receptor. Growth Factors 17: 25-35, 1999.

2. Silva M, Benito A, Sanz C, Prosper F, Ekhterae D, Nunez G and Fernandez-Luna JL: Erythropoietin can induce the expression of bcl-x $(\mathrm{L})$ through Stat5 in erythropoietin-dependent progenitor cell lines. J Biol Chem 274: 22165-22169, 1999.

3. Wojchowski DM, Gregory RC, Miller CP, Pandit AK and Pircher TJ: Signal transduction in the erythropoietin receptor system. Exp Cell Res 253: 143-156, 1999.

4. Juul SE, Anderson DK, Li Y and Christensen RD: Erythropoietin and erythropoietin receptor in the developing human central nervous system. Pediatr Res 43: 40-49, 1998.

5. Anagnostou A, Liu Z, Steiner M, Chin K, Lee ES, Kessimian N and Noguchi CT: Erythropoietin receptor mRNA expression in human endothelial cells. Proc Natl Acad Sci USA 91: 3974-3978, 1994.

6. Fraser JK, Tan AS, Lin FK and Berridge MV: Expression of specific high-affinity binding sites for erythropoietin on rat and mouse megakaryocytes. Exp Hematol 17: 10-16, 1989.
7. Acs G, Acs P, Beckwith SM, Pitts RL, Clements E, Wong K and Verma A: Erythropoietin and erythropoietin receptor expression in human cancer. Cancer Res 61: 3561-3565, 2001.

8. Westenfelder C and Baranowski RL: Erythropoietin stimulates proliferation of human renal carcinoma cells. Kidney Int 58: 647-657, 2000.

9. Arcasoy MO, Amin K, Chou SC, Haroon ZA, Varia M and Raleigh JA: Erythropoietin and erythropoietin receptor expression in head and neck cancer: relationship to tumor hypoxia. Clin Cancer Res 11: 20-27, 2005.

10. Acs G, Xu X, Chu C, Acs P and Verma A: Prognostic significance of erythropoietin expression in human endometrial carcinoma. Cancer 100: 2376-2386, 2004.

11. Junk AK, Mammis A, Savitz SI, et al: Erythropoietin administration protects retinal neurons from acute ischemia-reperfusion injury. Proc Natl Acad Sci USA 99: 10659-10664, 2002.

12. Kertesz N, Wu J, Chen TH, Sucov HM and Wu H: The role of erythropoietin in regulating angiogenesis. Dev Biol 276: 101-110, 2004.

13. Henke M, Laszig R, Rube C, et al: Erythropoietin to treat head and neck cancer patients with anaemia undergoing radiotherapy: randomised, double-blind, placebo-controlled trial. Lancet 362: $1255-1260,2003$

14. Leyland-Jones B, Semiglazov V, Pawlicki M, et al: Maintaining normal hemoglobin levels with epoetin alfa in mainly nonanemic patients with metastatic breast cancer receiving first-line chemotherapy: a survival study. J Clin Oncol 23: 5960-5972, 2005.

15. Yasuda Y, Musha T, Tanaka H, et al: Inhibition of erythropoietin signalling destroys xenografts of ovarian and uterine cancers in nude mice. Br J Cancer 84: 836-843, 2001.

16. Marti HH: Erythropoietin and the hypoxic brain. J Exp Biol 207: 3233-3242, 2004.

17. Wei L, Han BH, Li Y, Keogh C, Holtzman DM and Yu SP: Cell death mechanism and protective effect of erythropoietin after focal ischemia in the whisker-barrel cortex of neonatal rats. $\mathbf{J}$ Pharmacol Exp Ther 317: 109-116, 2005.

18. Brines ML, Ghezzi P, Keenan S, et al: Erythropoietin crosses the blood-brain barrier to protect against experimental brain injury. Proc Natl Acad Sci USA 97: 10526-10531, 2000.

19. Ehrenreich H, Hasselblatt M, Dembowski C, et al: Erythropoietin therapy for acute stroke is both safe and beneficial. Mol Med 8: 495-505, 2002.

20. Demetri GD, Kris M, Wade J, Degos L and Cella D: Quality-oflife benefit in chemotherapy patients treated with epoetin alfa is independent of disease response or tumor type: results from a prospective community oncology study. Procrit Study Group. J Clin Oncol 16: 3412-3425, 1998 .

21. Wun T, Law L, Harvey D, Sieracki B, Scudder SA and Ryu JK: Increased incidence of symptomatic venous thrombosis in patients with cervical carcinoma treated with concurrent chemotherapy, radiation, and erythropoietin. Cancer 98: 1514-1520, 2003.

22. Dolznig H, Habermann B, Stangl K, Deiner EM, Moriggl R, Beug $\mathrm{H}$ and Mullner EW: Apoptosis protection by the Epo target $\mathrm{Bcl}-\mathrm{X}(\mathrm{L})$ allows factor-independent differentiation of primary erythroblasts. Curr Biol 12: 1076-1085, 2002.

23. Weishaupt JH, Rohde G, Polking E, Siren AL, Ehrenreich H and Bahr M: Effect of erythropoietin axotomy-induced apoptosis in rat retinal ganglion cells. Invest Ophthalmol Vis Sci 45: 1514-1522, 2004.

24. Hardee ME, Rabbani ZN, Arcasoy MO, Kirkpatrick JP, Vujaskovic Z, Dewhirst MW and Blackwell KL: Erythropoietin inhibits apoptosis in breast cancer cells via an Akt-dependent pathway without modulating in vivo chemosensitivity. Mol Cancer Ther 5: 356-361, 2006. 